\begin{tabular}{|c|c|}
\hline 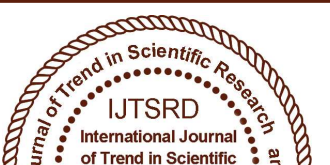 & $\begin{array}{l}\text { International Journal of Trend in Scientific } \\
\text { Research and Development (IJTSRD) }\end{array}$ \\
\hline 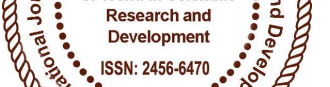 & International Open Access Journal \\
\hline 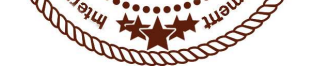 & ISSN No: 2456 - 6470 | www.ijtsrd.com | Volume - 2 | Issue - 4 \\
\hline
\end{tabular}

\title{
Do guests prefer Tech Savvy Rooms? A perspective from hotel guests
}

\author{
Dr. Seema Zagade \\ Professor, Maharastra State Institute of Hotel \\ Management and Catering Technology, Pune \\ Ph.D. Guide- Savitibai Phule Pune University
}

\author{
Ms. Meyola Fernandes \\ Assistant Professor, Accommodation Operations, \\ AISSMS-CHMCT, Shivaji Nagar, Pune, Maharashtra \\ Research Scholar, Savitribai Phule Pune University
}

\section{ABSTRACT}

More than ever before, technology today is having a substantial impact on business spheres, and the hotel industry is o exception. It has turned out to be a critical element with regards to guest satisfaction. The purpose of this study was dual: to understand the most common reasons for choosing a hotel to stay in and measure and document the guest satisfaction with the existing technologies offered in hotel guest rooms. A random sample of Indian travellers was taken into consideration for the study; a questionnaire was developed for hotel guests, generating a sample of 158 valid responses.

The results of the study revealed that Seamless unlimited Wi-Fi was the most important technology for both leisure and business travellers. The majority of respondents would prefer to experience new technologies in order to improve their experience.

Keywords: guestroom technology, technological amenities, guest experience, in room technology

\section{INTRODUCTION}

Technology has had a big impact on society all around and its importance has grown substantially during the past few decades. Keeping this view in mind, hotels need to follow the evolution of technology to attract guests and provide them with a unique experience. Some technology trends in industry are leading to great improvements and savings for the hospitality industry; while some are changing how hotel establishments plan their buildings, infrastructure, management structure and staffing requirements.
Technology already is an intrinsic and invaluable element of the total travel lifecycle, ranging from travellers using an assortment of devices to book hotels to connecting to Wi-Fi instantly upon arrival in the hotel.

It is extremely important for hotels to continue advancing in technology to enhance the guest experience. Outstanding hotel experiences are important not just to keep guests happy during their stay in the premises of the hotel, but also to influence their behaviour post-stay as well. Comments on social media are now the trend and are surely bound to rise, especially with the millennial travellers accounting for a greater share of travel activity.

Business guests and leisure travellers are on the constant look out for new experiences. As a matter of fact expectations of having access to the newest technology in hotels continue to increase. The growing level of technological acceptance by guests combined with the shorter life cycles of technology creates a major challenge for hotels. In the past, hotel guestrooms provided access to varied experiences with technology that potential hotel guests could not get in their homes a few years earlier. At the present time, this has changed completely wherein, in most cases, what guests have in their homes today is at times far more superior to anything that is available in hotel rooms (Horner, 2012). Therefore, it is necessary to provide in-room technology that reflects what is on the market now and what people are currently experiencing. Hotel guests expect to have access to the internet seamlessly and without any 
interruptions, leading hotels to invest in better, faster Wi-Fi infrastructure so that guests can conduct business and use their technology devices with ease during their stay.

In order to meet the rising demand of hotel guests, hotels today have incorporated modern technological trends in guestrooms such as Food tray trackers, Dash buttons, Video phones in rooms, In room interactive television, iPad, LCD Mirror television, Smart showers and Keyless room entry, to name a few.

\section{The purpose of this study was:}

1. To identify the main reasons for guests choosing a hotel to stay in.

2. To analyse the importance of technology with respect to guest experiences in hotels.

3. To ascertain whether the latest technologies in hotel guest experiences varies according to age group and purpose of travel.

\section{Literature Review:}

1. Ana carina freire margarido (2015) in her study mention that upmarket hotels operate in a very competitive market and therefore place a high amount of importance on emphasis providing quality service through the latest technological amenities. Of late hotel organisations are paying heed to the customers' desires in an effort to offer them a unique experience. Nevertheless, given the number of options available with respect to technologies in the market today, hoteliers have a very limited understanding of their guests' expectations and of which technological amenities will help achieve guest satisfaction. As technological items change rapidly over time, the study was carried out to analyse the impact of current technologies available as well as to assess the potential of the latest technologies on guest experience.

2. Chee Wah Peter Too (2010) in his research paper mentions the various types of technology and facility enhancement devices adopted by hoteliers for their guestrooms in order to meet the constantly increasing demand and expectation from the guests. The author also explores the technologies and devices that hotel operation heads use to influence business sustainability for daily operations. As a part of the corporate social responsibility, hotel owners are exploring the opportunities to increase certain activities through the use of modern technology to reduce damage to the environment by using energy saving devices in their properties. This paper as also provides a better understanding on the technologies adopted by hoteliers that have a positive impact on the environment without compromising the service level they deliver.

3. Cihan Cobanoglu (2011) states that technology is a vital determinant with regards to satisfaction of hotel guests. Hotels often make use of technology as a value-added amenity to help promote a sense of uniqueness and enhance guest satisfaction. This study to measures the level of guest satisfaction with the existing technology-based amenities in hotels, and examines the scope of impact of these amenities on overall hotel guest satisfaction.

4. SoYeon Jung (2014) This paper mentions the importance of hotel operators recognise in-room technology trends and as an effect the impact of inroom technology on business performance. The study also determines that setting up particular inroom technologies that have a significant effect on enhancing the customer experience and increasing hotel revenue. The study also mentions the most commonly installed in-room technologies that hoteliers plan to install in the near future

\section{Data Analysis and Interpretation}

Age of the respondents

\section{Age of Respondents}

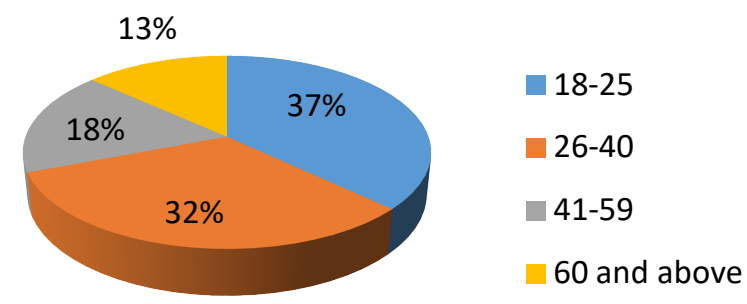

Figure 1

The above data is categorised by age of the respondents who travel. The data reflects that $37 \%$ of the respondents were between the age of 18-25 years, 32\% respondents were between the age of 26-40 years . A few respondents, $18 \%$, were between the age of 41-59 and only 13\% were older than 60 years. 


\section{Gender of Respondents}

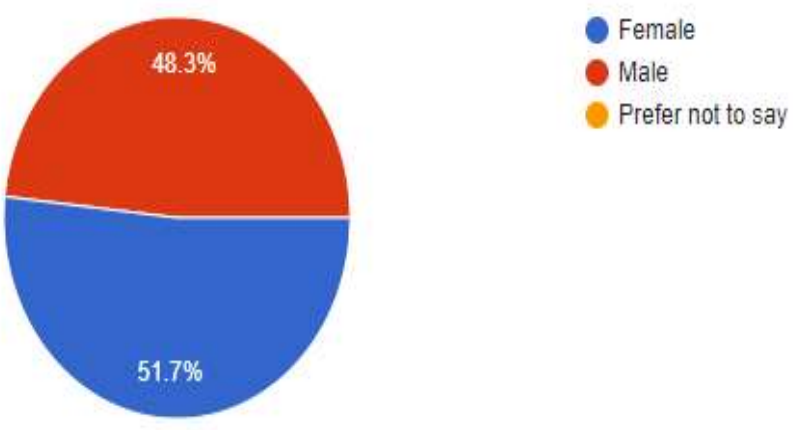

Figure 2

The questionnaire was distributed among 158 respondents out of which $51.7 \%$ were Female and $48.3 \%$ were Male.

\section{Marital Status of Respondents}

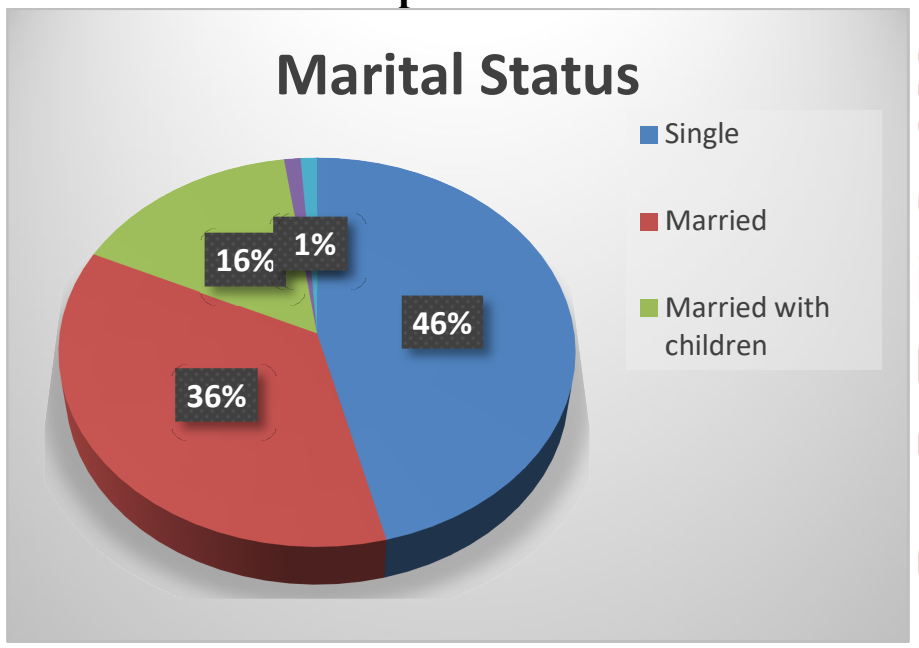

Figure 3

In terms of marital status, almost half of the respondents were single (46\%), and $36 \%$ were married or were cohabitating. The remainder of the respondents were married with children, $16 \%$ and just $1 \%$ were in a relationship.

\section{Educational qualification of Respondents}

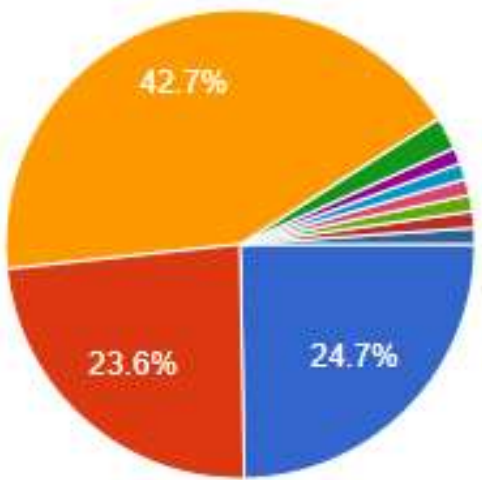

Undergraduate

Graduate

Post Graduate

Doctorate

HSC passed

$\mathrm{PhD}$

$\mathrm{Ph} D$

Diploma in Nautical sciences

\section{Figure 4}

With respect to the Educational Qualification of the respondents who filled out the questionnaire,the results show that $42.7 \%$ were had Post Graduate Degree, while $24.7 \%$ were Under Graduates and $23.6 \%$ were Graduates .The remaining respondents were varied such as,Doctorates, Ph.D holders, and from the Nautical Sciences background to name afew.

\section{Purpose of Travel}

\section{Purpose of Travel}
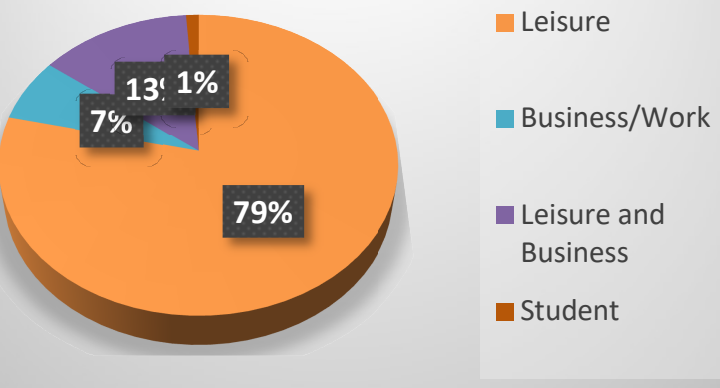

Figure 5 
When examining the purpose of travel of the respondents', the vast majority of respondents $79 \%$ were leisure guests, while $13 \%$ were travelling for both,Business and Leisure. A small portion of the sample $7 \%$ were travelling for Business. Almost $1 \%$ of the respondents said they travelled as a Student.

\section{How do you mostly travel ?}

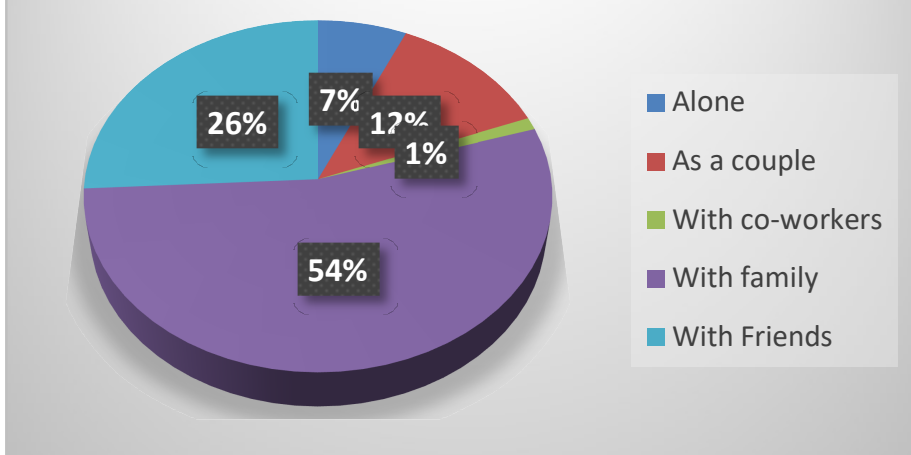

Figure 6

Another finding of this study indicates that almost $54 \%$ of respondents that stayed in hotels had travelled with Family. While $26 \%$ of the respondents travelled with Friends and 12\% travelled as a couple. Just 7\% travelled Alone and 1\% with co-workers for the purpose of attending meetings or conferences.

\section{Vital Reasons for choosing a hotel to stay in.}

\section{Reasons for choosing a hotel to stay in}

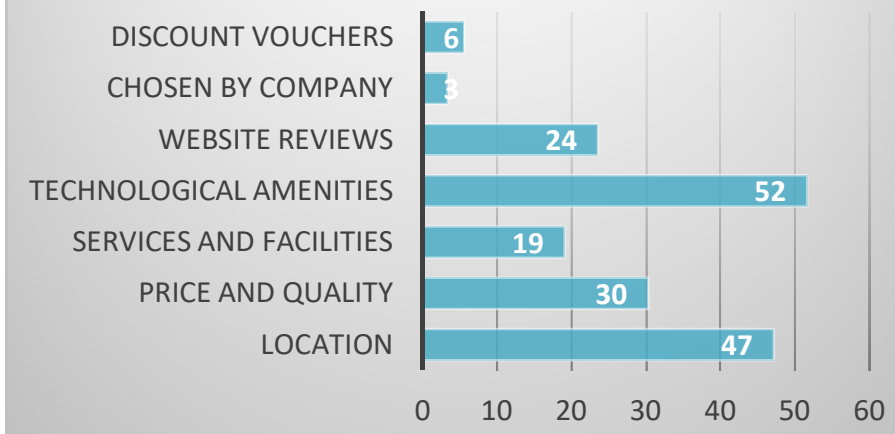

Figure 7
Typically the most common reason for guests to choose a hotel would be the location of the property, but the data collected suggests that Location comes a close second,(47\%), whereby making Technological Amenities prevailing in hotels $(52 \%)$ the top choice of hotel guests. The price and quality of the hotel room $(30 \%)$ and other guest room service and amenities(19\%), and choosing a hotel on the basis of website reviews is $24 \%$. Discount vouchers and Chosen by company is rated by $6 \%$ and $3 \%$ of hotel guests.

\section{Number of devices that a Hotel Guest travels with.}

\section{How many Devices do you Travel with?}

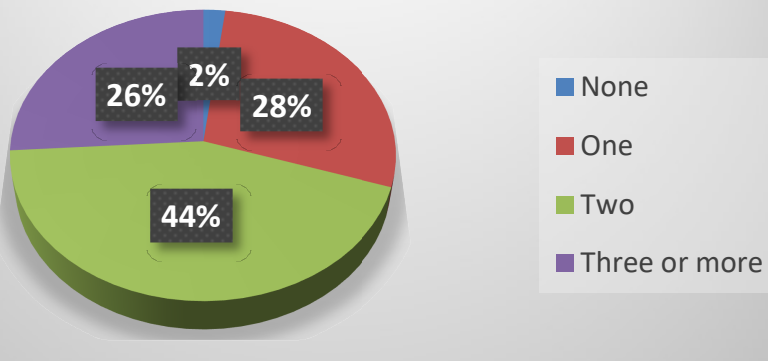

Figure 8

Apart from just travelling with their smartphones and laptops, more and more guests today travel with devices such as iPod,iPad,Tablets and other streaming devices. Of late many guests are bringing their own content when they stay in a hotel, which they can access through Smart Televisions in the guestrooms. The adata collected states that $44 \%$ of hotel guests travel with atleast two devices, $26 \%$ tend to travel with three or more devices whereas $28 \%$ with one device and a relatively low amount of hotel guests, $2 \%$ travel with no device.

\section{Guests acknowledgement of Hotel Technological Amenities}




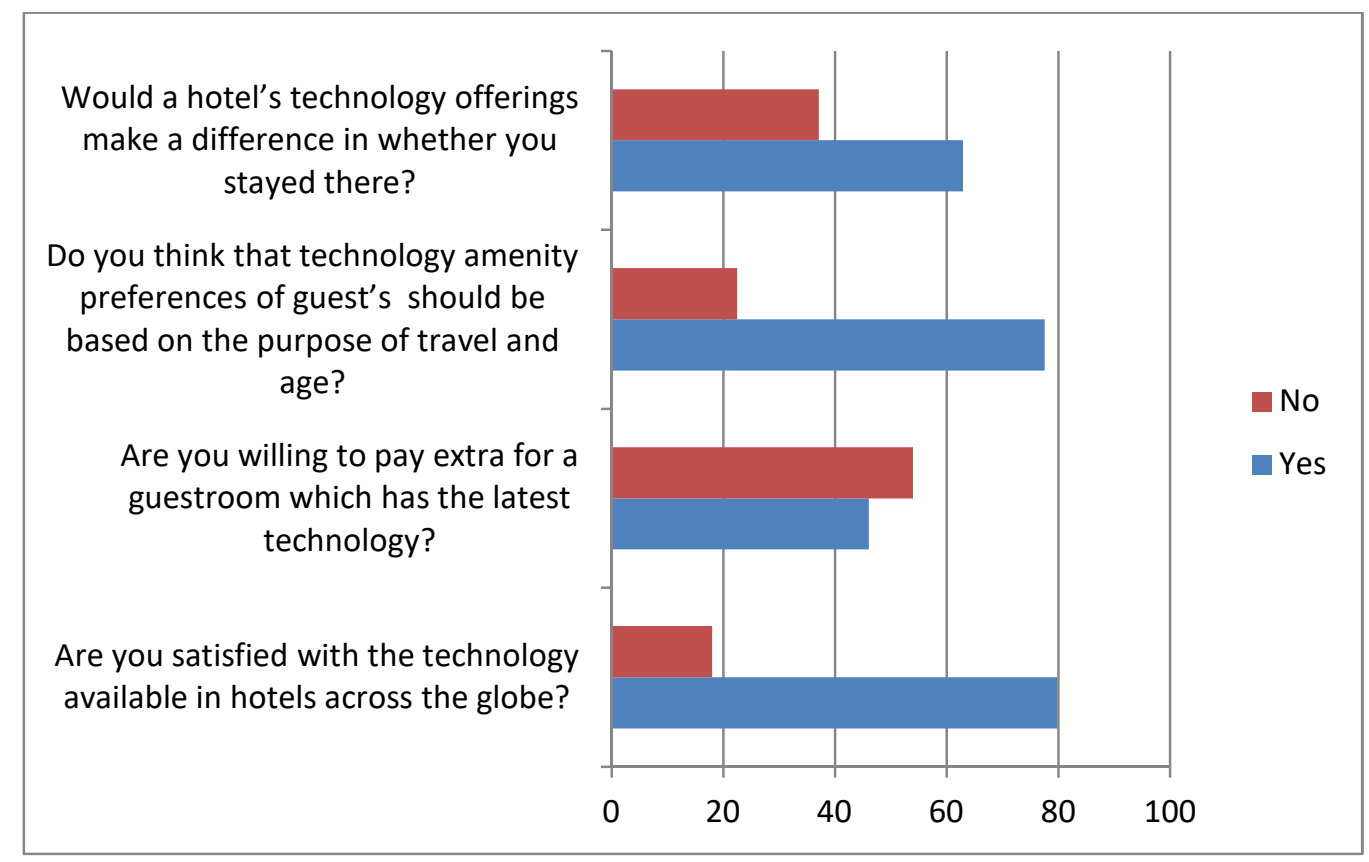

Figure 9

Data collected to understand the acknowledgement of hotel guest with respect to certain aspects of technology in hotel rooms, displyed the following results. $80 \%$ of of mentioned that they are satisfied with the various technologies available in hotels across the globe while $18 \%$ state that it could be better improved or newer technologies introduced. $46 \%$ guests say that they are willing to pay extra for a hotel room which provides them with the latest technology. $78 \%$ agree that technoloical amenity prefernces of guests should be based on the purpose of travel and age of the potential traveller as compared to $22 \%$ who did not agree with the above. $63 \%$ of hotel guests mention that there would be a definite difference in the choice of hotel to reside in, depending upon the hotels technology offerings, while $37 \%$ state that technology offerings of a hotel would not make a difference while choosing a hotel to reside in.

Technological amenities in hotel rooms that guest would prefer while visiting a hotel. 


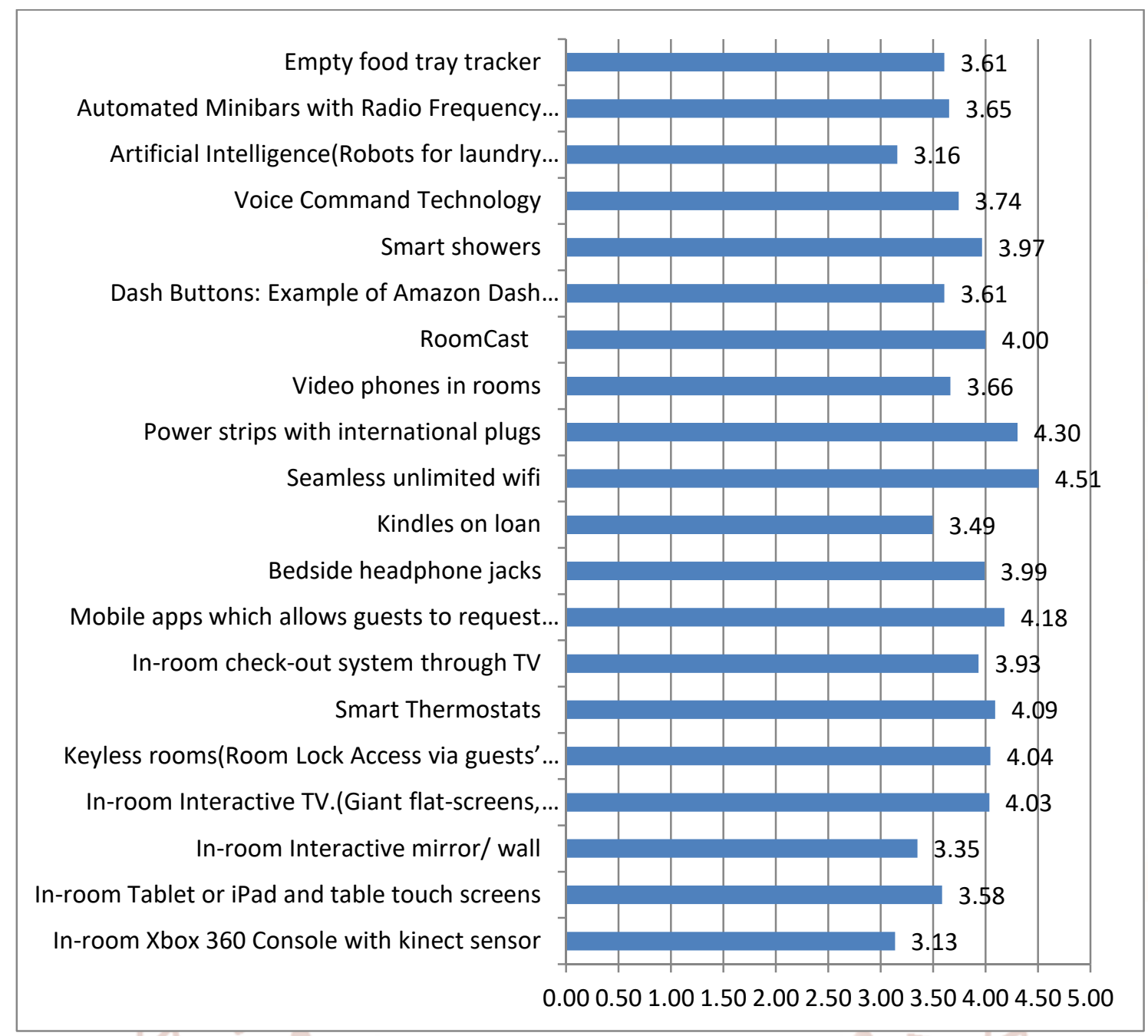

\section{Figure 10}

Respondents were asked to state their preference from a scale of 1 to 5 on the 20 listed technological amenities in hotel guest rooms that would enhance your stay. Likert's Scale was used for the rating whereby, $1=$ strongly disagree, $2=$ disagree, $3=$ neutral, $4=$ agree, $5=$ strongly agree.

Mentioned below is the list of latest Technological Amenities that help enhance the Guest their stay in a hotel.

\begin{tabular}{|l|l|}
\hline $\begin{array}{l}\text { Sr. } \\
\text { No }\end{array}$ & Technological amenity in Hotel Guest rooms \\
\hline 1 & In-room Xbox 360 Console with kinect sensor \\
\hline 2 & In-room Tablet or iPad and table touch screens. \\
\hline 3 & In-room Interactive mirror/ wall \\
\hline 4 & In-room Interactive TV.(Giant flat-screens, HD, 3D and 4K TV) \\
\hline 5 & Keyless rooms (Room Lock Access via guests' mobile phone) \\
\hline 6 & $\begin{array}{l}\text { Smart Thermostats (technology that will allow guests to adjust the temperature in their } \\
\text { rooms with a smartphone, even if they aren't on the premises) }\end{array}$ \\
\hline 7 & In-room check-out system through TV \\
\hline 8 & $\begin{array}{l}\text { Mobile apps which allows guests to request everything from fresh towels to a turndown } \\
\text { service }\end{array}$ \\
\hline 9 & Bedside headphone jacks \\
\hline
\end{tabular}


International Journal of Trend in Scientific Research and Development (IJTSRD) ISSN: 2456-6470

\begin{tabular}{|l|l|}
10 & Kindles on loan \\
\hline 11 & Seamless unlimited Wi-Fi \\
\hline 12 & Power strips with international plugs \\
\hline 13 & Video phones in rooms \\
\hline 14 & $\begin{array}{l}\text { Room Cast (a mobile streaming service for the hospitality industry from TeleAdapt) } \\
\text { enabled apps, including Netflix, YouTube, HBO and Spotify }\end{array}$ \\
\hline 15 & Dash Buttons: Example of Amazon Dash button. Push to order new toilette paper \\
\hline 16 & $\begin{array}{l}\text { Smart showers: Smart showers automatically control the temperature and power of your } \\
\text { water with pre-set preferences. Shower stalls that turn the glass from clear to frosted } \\
\text { with the touch of a button }\end{array}$ \\
\hline 18 & $\begin{array}{l}\text { Voice Command Technology (placed by the bedside console and equipped to } \\
\text { understand voice commands) }\end{array}$ \\
\hline 19 & Automated Minibars with Radio Frequency Identification (RFID) \\
\hline 20 & Empty food tray tracker \\
\hline
\end{tabular}

The study revealed that Seamless Unlimited Wi-Fi (Internet access) was the most important technology for hotel travellers with the highest Mean of 4.51. This reflects that as most guests' today travel with multiple devices, having a high speed internet or WiFi connection is vital. Power strips with international plugs (4.30) ranks a close second, and Mobile apps which allows guests to request everything from fresh towels to a turndown service (4.18) ranks third primarily due to the need for guests wanting to be empowered when they stay in hotels. Smart Thermostats (technology that will allow guests to adjust the temperature in their rooms with a smartphone, even if they aren't on the premises) has a Mean of 4.09 and ranks fourth in the technological amenities desired by hotel guests. Keyless rooms (Room Lock Access via guests' mobile phone) with a mean of 4.04 was also considered to be important.

Technological amenities that have been rated lower on the overall spectrum include In-room Xbox 360 Console with kinect sensor 3.13,Artificial Intelligence (Robots for laundry valet, newspaper delivery etc.) 3.16, In-room Interactive mirror/ wall is 3.35, Dash Buttons: Example of Amazon Dash button,3.61, Empty food tray tracker 3.61, Automated Minibars with Radio Frequency Identification (RFID) rated at 3.65 Mean.

\section{Conclusion}

With technology progressing in such a fast pace, the key requirement for every hotel in enhancing the guest experience and increasing repeat business, is staying ahead of changes. The challenge here is in keeping up with the guest, who are already tech savvy and desire technology at every step of the way,especially while they travel to keep them connect with Business and acquaintances.

Incidentally, technology is being taken out of the hands of the hotelier and put into the hands of the guest allowing them greater control over their individual experience by also empowering them to make decisions that directly concern them during their stay.

The study also states that most of the travellers today who stay in hotels are millennials who travel with family for leisure purposes and who have a tendency to choose a hotel for the type and amount of Technological amenities it provides, irrespective if the amenity is charged or complimentary. Among all the Technological amenities provided to the hotel guest the most favoured is Seamless Unlimited Wi-Fi (Internet access), due to the number of devices they travel with and the need to have access to products and services at the touch of a button. 


\section{Bibliography and References}

1) Ana carina freire margarido (2015) the impact of technological amenities on customer experience in upscale hotels September, 2015

2) Chee Wah Peter Too (2010), Technology enhancement in hotel guestroom.

3) http://digitalscholarship.unlv.edu/thesesdissertatio $\underline{\mathrm{ns}}$

6) Horner,T (2012)TOP Hotel Technology Trends in 2012, Hotel Business Review. Retrieved from http://hotelexecutive.com/business_review/2888/t op-hotel-technology-trends-in-2012.

7) https://www.fodors.com/news/10-techsavvy-hotelinnovations- 6750

8) http://www.hotel-online.com/archive/archive4914

4) The Impact of Technology Amenities on Hotel Guest Overall Satisfaction Cihan Cobanoglu Journal of Quality Assurance in Hospitality \& Tourism Volume 12, 2011 - Issue 4

5) SoYeon Jung, Jungsun (Sunny) Kim, John Farrish, (2014) "In-room technology trends and their implications for enhancing guest experiences and revenue", Journal of Hospitality and Tourism Technology, Vol. 5 Issue: 3, pp.210228, https://doi.org/10.1108/JHTT-11-2013-0035

9) http://www.allotz.com/blog/do-guests-want-techsavvy-hotel-rooms

10) https://www.fodors.com/news/10-techsavvy-hotelinnovations- 6750

11) https://insights.samsung.com/2015/10/23/hospitali ty-technology-creates-an-innovative-atmospherefor-business-travelers-case-study/

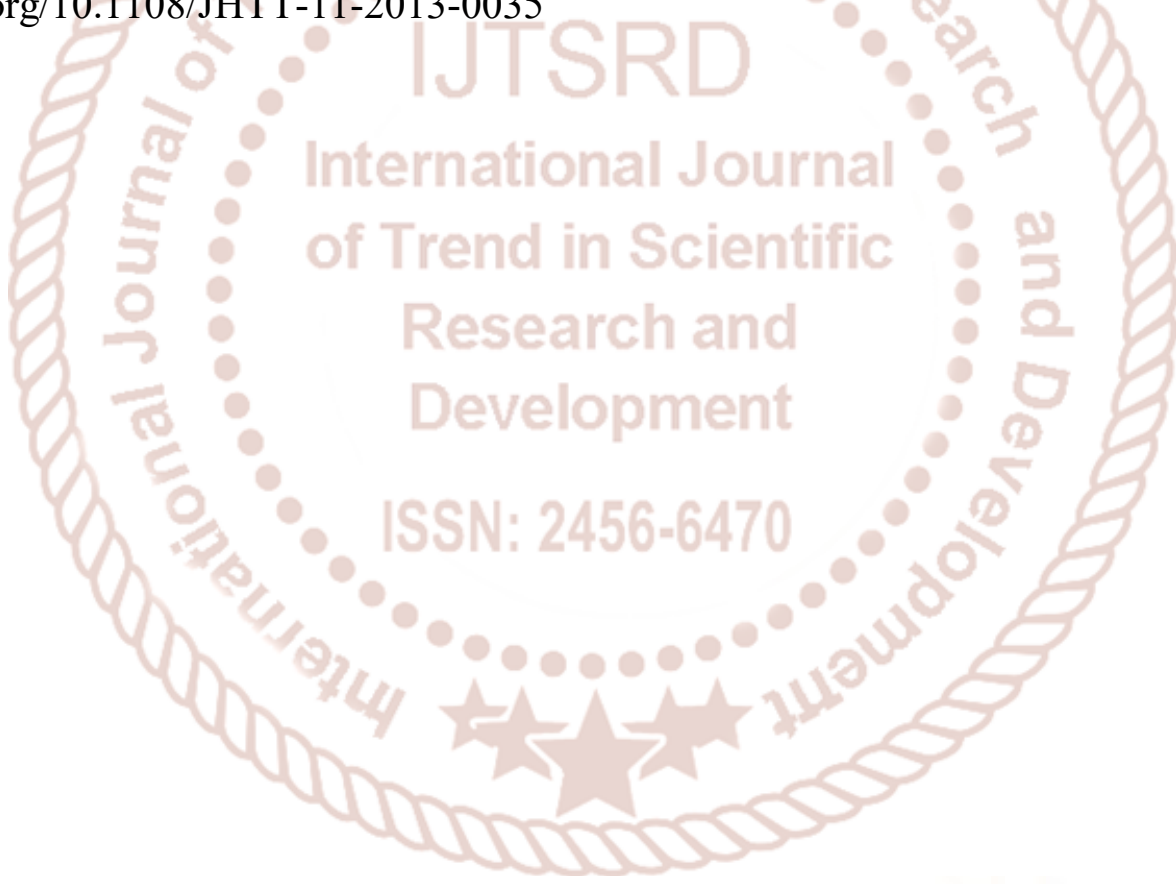

